\title{
UN NUEVO GÉNERO DE CRUCIFERAE (BRASSICACEAE) DEL ESTADO DE GUERRERO, MÉXICO*
}

\author{
Nelly Diego Pérez ${ }^{1}$ y Graciela Calderón de Rzedowski² \\ ${ }^{1}$ Laboratorio de Plantas Vasculares, Facultad de Ciencias, Universidad Nacional \\ Autónoma de México, Apdo. postal 70-282, 04510 México, D.F. \\ ${ }^{2}$ Instituto de Ecología, A.C. Centro Regional del Bajío, Apdo. postal 386 \\ 61600 Pátzcuaro, Michoacán
}

\begin{abstract}
RESUMEN
Se propone a Lexarzanthe como género nuevo basado en Romanschulzia mexicana, taxon descrito originalmente de Guerrero con fundamento en ejemplares en fructificación. Las recientes colectas de la misma planta en flor, indican que la especie difiere de Romanschulzia en sus inflorescencias extendidas, corimbiformes, con pedicelos muy largos y delgados, sus flores de mucho mayor tamaño, con sépalos y pétalos erectos y persistentes en la antesis, así como sus estambres pronunciadamente exsertos.

Dadas estas discrepancias, la planta debe ubicarse en un género distinto, también perteneciente a la tribu Thelypodieae, pero al parecer más cercanamente relacionado con Warea y con Stanleya, entidades consideradas como primitivas dentro de la familia Cruciferae.
\end{abstract}

Palabras clave: Brassicaceae, Cruciferae, Guerrero, México, Romanschulzia.

\begin{abstract}
Lexarzanthe is proposed as a new genus of the Cruciferae on the basis of Romanschulzia mexicana, a species originally described from fruiting material collected in the Mexican state of Guerrero. Recent collections of the same plant obtained in flowering condition reveal that this species differs from Romanschulzia in its ample corymbiform inflorescence with long and slender pedicels, in its much larger flowers with erect sepals and petals which persist during anthesis, as well as in its notably exserted stamens.
\end{abstract}

\footnotetext{
*Trabajo realizado con apoyo económico del Instituto de Ecología, A. C. (cuenta 902-07), del Consejo Nacional de Ciencia y Tecnología y de la Comisión Nacional para el Conocimiento y Uso de la Biodiversidad.
} 
In view of these differences the plant should be placed in a separate genus, which also belongs in the tribe Thelypodieae, but seems to be more closely related to Warea and Stanleya, genera considered as primitive in the family.

Key words: Brassicaceae, Cruciferae, Guerrero, Mexico, Romanschulzia.

En junio de 1985 W. Thomas y J. L. Contreras colectaron en el estado de Guerrero (municipio de Chichihualco de Leonardo Bravo) ejemplares carentes de flores de una planta escandente, que por las características de su infrutescencia inicialmente se concibió como miembro de la familia Capparaceae.

Sin embargo, el estudio más detallado de su fruto y de sus semillas llevó a la deducción de que se trata de un componente de las Cruciferae y consecuentemente Al-Shehbaz e Iltis (1993) lo describieron como Romanschulzia mexicana.

En marzo de 1998, N. Diego, B. Ludlow y A. Acosta, en un área vecina del municipio de General Heliodoro Castillo (Tlacotepec) volvieron a encontrar la misma especie, esta vez en flor y fruto. El examen de tales materiales más completos confirma su ubicación en la familia Cruciferae, pero dadas las peculiaridades de la flor y de la inflorescencia, conduce a la conclusión de que no se trata de un miembro de Romanschulzia, sino de un género independiente.

LEXARZANTHE N. Diego \& Calderón gen. nov.

Herbae vel subfrutices scandentes; folia infera petiolata, supera sessilia et auriculata vel amplexicaulia; inflorescentia terminalis corymbosa ampla et extensa, pedicellis filiformibus; sepala 4 erecta, sub anthesi persistentia; petala 4 albo-flavida spathulata erecta, quam sepala paulo longiora; stamina 6 subaequalia longe exserta, antheris sagittatis post dehiscentiam non tortis; ovarium biloculare longo gynophoro subtentum; fructus anguste cylindricus; semina cotyledonibus incumbentibus.

Plantas herbáceas o subfrutescentes, trepadoras, glabras; tallos rollizos, sólidos, ramificados; hojas inferiores pecioladas, las próximas a la inflorescencia sésiles y auriculadas a amplexicaules; inflorescencia en forma de corimbo terminal, multifloro, ebracteado, pedúnculo ausente, pedicelos filiformes, muy alargados; botones florales globosos a obovoides, flores hermafroditas, actinomorfas, tetrámeras; cáliz tubular, sépalos erectos, persistentes en la antesis, estrechamente oblongos, con la base levemente sacciforme; pétalos angostamente espatulados, un poco más largos que los sépalos, blanco-amarillentos, también erectos y persistentes en la antesis; estambres 6, subiguales, largamente exsertos, filamentos llegando a medir cerca del 
doble del largo de la corola, sus bases insertas en el anillo nectarífero, anteras sagitadas en la base, subbasifijas, sin enroscarse después de la dehiscencia; ovario cilíndrico, provisto de ginóforo, bilocular, estilo corto, cilíndrico, estigma pequeño, entero; fruto angostamente cilíndrico, sostenido por un ginóforo alargado, septo membranáceo completo, cada lóculo con varias semillas dispuestas en una sola hilera; semillas oblongas, cotiledones incumbentes.

El nombre del género se dedica como homenaje a la memoria del destacado naturalista mexicano Juan José Martínez de Lexarza (1785-1824), quien en su corta pero fructífera existencia destacó entre otras actividades en el estudio de la flora del país.

En vista de sus flores tubulosas, estambres subiguales, exsertos, anteras sagitadas en la base, ginóforo conspicuo y fruto rollizo, Lexarzanthe se ubica en la tribu Thelypodieae, como la ha definido Al-Shehbaz (1973), y que se considera como el conjunto primitivo de la familia Cruciferae.

A su vez, los estambres exsertos, los ginóforos alargados y la inflorescencia corimbiforme acercan al género nuevo a Warea, conjunto de 4 especies conocidas del sureste de Estados Unidos, principalmente de Florida (Rollins, 1993). Sin embargo, Warea difiere en sus sépalos extendidos a reflejos, no sacciformes en la base y en los pétalos notablemente unguiculados.

Otro género indudablemente relacionado es Stanleya, del que se conocen seis especies habitantes de regiones áridas del oeste estadounidense (Rollins, op. cit.), con el que coincide también Lexarzanthe en los caracteres de estambres exsertos y de ginóforos alargados, pero que se distingue por su inflorescencia racemosa, así como por sus sépalos lineares, extendidos o reflejos.

Los tres géneros en cuestión pueden separarse entonces mediante la siguiente clave, adaptada en parte de la de Al-Shehbaz (1973):

1. Sépalos y pétalos erectos; uñas de los pétalos y filamentos desprovistos de pubescencia y de tubérculos, inflorescencia corimbosa; planta trepadora, del estado de Guerrero, México

Lexarzanthe

1. Sépalos y pétalos extendidos o reflejos; uñas de los pétalos y/o filamentos por lo general provistos de pubescencia o tubérculos; inflorescencia corimbosa o racemosa; plantas erectas, de Estados Unidos.

2. Flores amarillas a blanquecinas; inflorescencia racemosa; plantas del oeste de Estados Unidos Stanleya

2. Flores blancas a moradas; inflorescencia corimbosa; plantas del sureste de Estados Unidos Warea 
A su vez el género Romanschulzia se encuentra más alejado que los anteriores y por principio se distingue de Lexarzanthe mediante las siguientes características:

\begin{tabular}{|l|l|}
\hline \multicolumn{1}{|c|}{ Lexarzanthe } & \multicolumn{1}{c|}{ Romanschulzia } \\
\hline tallo trepador & tallo erecto \\
\hline inflorescencia corimbosa & inflorescencia racemosa \\
\hline $\begin{array}{l}\text { sépalos persistentes y erectos durante } \\
\text { la antesis, algo sacciformes en la base }\end{array}$ & $\begin{array}{l}\text { sépalos caducos o pronto caedizos, } \\
\text { no sacciformes en la base }\end{array}$ \\
\hline $\begin{array}{l}1.2 \text { a } 1.4 \text { cm de largo } \\
\text { pétalos erectos en la antesis, de } \\
\text { (1 cm más allá de los pétalos) } \\
\text { de } 7 \text { mm de largo, a veces ausentes }\end{array}$ \\
\hline $\begin{array}{l}\text { ginóforo hasta de } 3.2 \mathrm{~cm} \text { de largo } \\
\text { estambres inclusos o ligeramente } \\
\text { exsertos (menos de } 3 \text { mm más allá de } \\
\text { los pétalos) }\end{array}$ \\
\hline $\begin{array}{l}\text { ginóforo ausente o hasta de } 6 \text { mm de } \\
\text { largo }\end{array}$ \\
\hline
\end{tabular}

Consecuentemente la especie tipo de Lexarzanthe queda definida como:

Lexarzanthe mexicana (Al-Shehbaz \& Iltis) N. Diego \& Calderón comb. nov. (Fig 1). Romanschulzia mexicana Al-Shehbaz \& Iltis, Novon 3: 96. 1993. Tipo: México: Guerrero: municipio de Leonardo Bravo, Pedregal, $28 \mathrm{~km}$ by road WSW of Filo de Caballo, 10.VI.1985. W. Thomas \& J. L. Contreras 3788 (holotipo NY, fotografía IEB!; isotipo WIS; fragmentos MEXU!, UC).

Planta herbácea a subfrutescente, trepadora, hasta de $2.5 \mathrm{~m}$ de alto, glabra; porciones subterráneas y hojas de la parte basal desconocidas; hojas de la parte media de la planta con peciolos hasta de $1 \mathrm{~cm}$ de largo, las superiores sésiles, auriculadas a amplexicaules, láminas lanceoladas a ampliamente lanceoladas, de 3 a $11 \mathrm{~cm}$ de largo y 1 a $3 \mathrm{~cm}$ de ancho, ápice acuminado, borde levemente aserrado, 


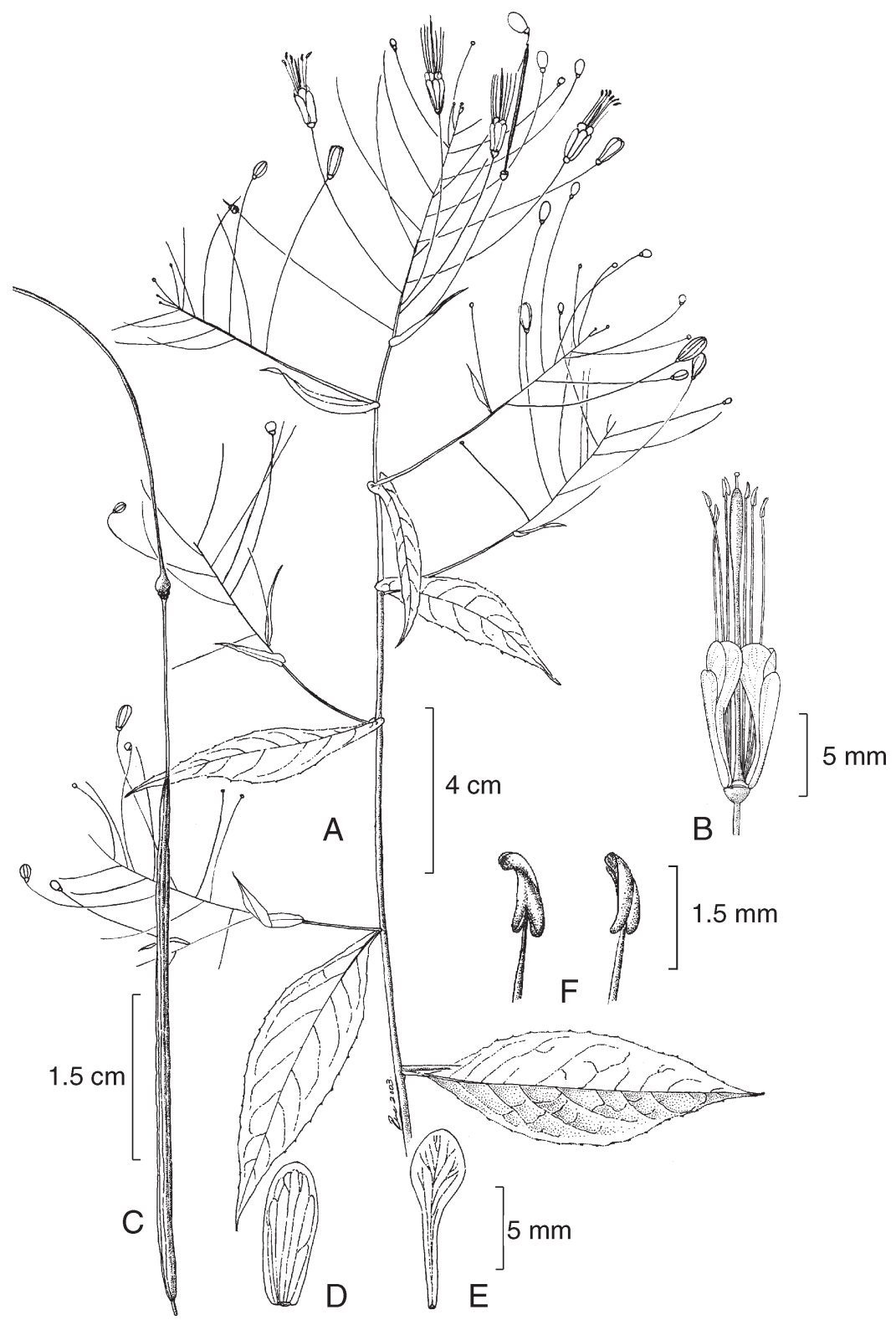

Fig. 1. Lexarzanthe mexicana. A. rama con hojas y flores; B. flor; C. fruto; D. sépalo; E. pétalo; F. anteras. 
base cuneada a auriculada; inflorescencias terminales, erectas, extendidas, originadas sobre ramas de la porción superior de la planta, dispuestas a manera de racimos corimbiformes de 5 a $13 \mathrm{~cm}$ de largo, con 12 a 25 flores, que en su conjunto semejan una panícula algo foliosa de 17 a $24 \mathrm{~cm}$ de largo y 20 a $24 \mathrm{~cm}$ de ancho, pedicelos floríferos muy finos, extendidos, ascendentes, de 5 a $7 \mathrm{~cm}$ de largo; flores hermafroditas, actinomorfas, con receptáculo de alrededor de $2 \mathrm{~mm}$ de diámetro; sépalos 4, persistentes y erectos durante la antesis, oblongos, de color verdeamarillento, de 1 a $1.2 \mathrm{~cm}$ de largo por 2 a $3 \mathrm{~mm}$ de ancho, glabros, muy ligeramente sacciformes en la base, a veces con una banda periférica escariosa de unos $0.5 \mathrm{~mm}$ de ancho, venación longitudinal, paralela; pétalos 4 , persistentes y erectos en la antesis, angostamente espatulados, blanco-amarillentos, de 1.2 a $1.4 \mathrm{~cm}$ de largo por 2.5 a $3.5 \mathrm{~mm}$ de ancho, glabros, venación reticulada; estambres 6 , subiguales, filamentos algo aplanados, de $2.1 \mathrm{a} 2.7 \mathrm{~cm}$ de largo, glabros, exsertos de la corola por alrededor de $1 \mathrm{~cm}$, anteras sagitadas, subbasifijas, rectas o apenas ligeramente encorvadas, de 2 a $2.3 \mathrm{~mm}$ de largo, sin enroscarse después de la dehiscencia; ovario cilíndrico, provisto de un ginóforo evidente, estilo hasta de $1 \mathrm{~mm}$ de largo, estigma corto, entero o en ocasiones levemente bilobado; infrutescencia laxa, colgante, pedicelos fructíferos fuertemente arqueados, filiformes, de 4 a $8 \mathrm{~cm}$ de largo y $0.3 \mathrm{~mm}$ de diámetro; ginóforo hasta de $3.2 \mathrm{~cm}$ de largo por $0.5 \mathrm{~mm}$ de diámetro, estriado; fruto cilíndrico, hasta de $6.5 \mathrm{~cm}$ de largo y $0.8 \mathrm{~mm}$ de diámetro, pico de aproximadamente $1.5 \mathrm{~mm}$ de largo, por lo común truncado, valvas con varias nervaduras longitudinales más o menos prominentes, septo delgado, de trayecto serpenteante, alternadamente empujado por las semillas hacia ambas valvas; semillas dispuestas en una sola hilera en cada lóculo, alrededor de 10 en total, oblongas, muy ligeramente aplanadas, subcuadrangulares en corte transversal, de 2.5 a $3.6 \mathrm{~mm}$ de largo y 1 a $1.3 \mathrm{~mm}$ de ancho, testa café-amarillenta, muy finamente reticulada.

Material adicional examinado: México: Guerrero: municipio de General Heliodoro Castillo, El Jilguero, alt. 2600 m, bosque mesófilo de montaña, suelo pedregoso, 1.III. 1998, N. Diego, B. Ludlow y A. Acosta 7724 (FCME, IEB); ibid., 25.VI.1998, N. Diego, B. Ludlow y A. Acosta 7865 (FCME, IEB).

En sus etiquetas Diego et al. indican que se trata de una planta escasa, hecho que queda confirmado por la circunstancia de que esta área de la Sierra Madre del Sur ya ha sido bastante explorada por numerosos colectores desde 1940, pero hasta la fecha al parecer la especie no ha sido localizada más que tres veces, a pesar de su vistosa apariencia.

Thomas y Contreras la registran de un malpaís o pedregal calcáreo, mientras Diego et al. la hallaron en suelo pedregoso en medio del bosque mesófilo de montaña. 
De esta información cabe deducir que se trata de un elemento rupícola de ambientes de clima relativamente húmedo, a más de $1800 \mathrm{~m}$ de altitud.

Florece en febrero y marzo, tal vez también en abril, o sea con antelación a la época lluviosa del año. Permanece con frutos maduros al menos hasta junio.

Las llamativas flores de Lexarzanthe mexicana son sin duda el resultado de la adaptación a un polinizador específico, posiblemente una especie de mariposa.

\section{AGRADECIMIENTOS}

Las autoras dan las gracias a Jerzy Rzedowski, de quien se recibió apoyo en la traducción de la diagnosis latina y en otros detalles de la preparación del manuscrito. Igualmente se agradece a Ramiro Cruz por la manufactura de la ilustración.

\section{LITERATURA CITADA}

Al-Shehbaz, I. A. 1973. The biosystematics of the genus Thelypodium (Cruciferae). Contr. Gray Herb. 204: 3-157.

Al-Shehbaz, I. A. \& H. H. Iltis. 1993. Romanschulzia mexicana (Brassicaceae), a remarkable new species from Guerrero, Mexico. Novon 3: 96-98.

Rollins, R. C. 1993. The Cruciferae of continental North America. Stanford University Press. Stanford, California. $976 \mathrm{pp}$. 